\title{
Etiological prevalence of epilepsy and epileptic seizures in hospitalized elderly in a Brazilian tertiary center - Salvador - Brazil
}

\author{
Prevalência etiológica de epilepsia e crises epilépticas em idosos hospitalizados em \\ centro terciário - Salvador - Brasil
}

Telma Rocha de Assis ${ }^{1}$, Aroldo Bacellar ${ }^{1}$, Gersonita Costa ${ }^{1}$, Osvaldo J. M. Nascimento²

\begin{abstract}
Epilepsy in the elderly has high incidence and prevalence and is often underecognized. Objective: To describe etiological prevalence of epilepsy and epileptic seizures in elderly inpatients. Methods: Retrospective analysis was performed on elderly patients who had epilepsy or epileptic seizures during hospitalization, from January 2009 to December 2010. One hundred and twenty patients were enrolled. They were divided into two age subgroups (median 75 years) with the purpose to compare etiologies. Results: The most common etiology was ischemic stroke (36.7\%), followed by neoplasias (13.3\%), hemorrhagic stroke (11.7\%), dementias (11.4\%) and metabolic disturbances (5.5\%). The analysis of etiological association showed that ischemic stroke was predominant in the younger subgroup (45\% vs $30 \%)$, and dementias in the older one (18.9\% vs $3.8 \%)$, but with no statistical significance $(p=0.23)$. Conclusion: This study suggests that epilepsy and epileptic seizures in the elderly inpatients have etiological association with stroke, neoplasias and dementias.
\end{abstract}

Keywords: elderly, epilepsy, epileptic seizures, etiology, prevalence.

\section{RESUMO}

Epilepsia no idoso tem alta incidência e prevalência e é frequentemente sub diagnosticada. Objetivo: Descrever a prevalência etiológica da epilepsia e crises epilépticas em idosos internados. Métodos: Estudo retrospectivo, envolvendo idosos hospitalizados, de 60 anos ou mais, que foram admitidos de janeiro de 2009 a dezembro de 2010 por terem apresentado epilepsia e crises epilépticas durante a hospitalização. Cento e vinte pacientes foram incluídos no estudo. Os pacientes foram divididos em dois subgrupos de idade (mediana 75 anos), com o propósito de comparar etiologias. Resultados: A etiologia mais comum foi o acidente vascular cerebral isquêmico (36,7\%), seguido por neoplasias (13,3\%), acidente vascular cerebral hemorrágico (11,7\%), demências $(11,4 \%)$ e distúrbios metabólicos (5,5\%). A análise da associação etiológica mostrou que o acidente vascular cerebral isquêmico predominou no subgrupo mais jovem (45\% vs 30\%), e as demências no subgrupo mais velho (18,9\% vs 3,8\%), contudo essa diferença não evidenciou significância estatística $(p=0,23)$. Conclusão: Este estudo sugere que epilepsia e crise epiléptica em idosos internados têm associação etiológica com acidente vascular cerebral, neoplasias e demências.

Palavras-chave: crise epiléptica, epilepsia, etiologia, idosos, prevalência.

Epilepsy is a chronic neurological condition characterized by recurrent epileptic seizures ${ }^{1}$. It is the third most frequent, serious and chronic neurological disorder in the elderly following stroke and dementia ${ }^{2}$. Epilepsy and epileptic seizures in the elderly present clinical features that differ from those that occur in younger individuals.

Demography profile in developed and developing countries is changing with increasing life expectation, thus the elderly comprise the fastest growing group of the population. It is estimated that for the year $2020,50 \%$ of new cases of epilepsy will be diagnosed in elders ${ }^{3}$. People over 75 years account for higher incidence of acute symptomatic seizures, epilepsy and status epilepticus compared to other age groups ${ }^{4}$. Moreover, currently 25 to $30 \%$ of new onset epilepsy is diagnosed in elders ${ }^{4,5}$.

The prevalence of active epilepsy in the elderly is up to $1.5 \%$, almost three times higher than in younger adults, but among nursing home residents may exceed $5 \%^{6}$.

Although the high incidence of epilepsy, the prevalence is relatively low possibly because of the high mortality for old-aged

${ }^{1}$ Hospital São Rafael, Departamento de Neurologia, Salvador BA, Brazil;

${ }^{2}$ Universidade Federal Fluminense, Departamento de Neurologia, Rio de Janeiro RJ, Brazil.

Correspondence: Telma M. Rocha de Assis; Av São Rafael, 2152; 41253-190 Salvador BA, Brasil; E-mail: telmasaj@gmail.com

Conflict of interest: There is no conflict of interest to declare.

Received 19 July 2014; Received 17 October 2014; Accepted 05 November 2014. 
people secondary to etiology of the epilepsy ${ }^{2,7}$. Despite its high incidence, epilepsy in old-aged people often goes underecognized and even neglected being a significant public health problem. Even after the advent of imaging techniques, as many as 25 to $40 \%$ of new epilepsy cases in elders have no obvious underlying etiology ${ }^{8}$.

Risk factors for epilepsy and seizures etiology vary with age. Whilst genetic and congenital diseases are predominantly associated with epilepsy in children and youth age, cerebrovascular disease (CVD) is the most common risk factor for epilepsy and seizures in older age ${ }^{9}$. Stroke is the most important underlying etiology of new-onset epilepsy in people 65 years old and older reaching 30 to $50 \%$ of cases where the cause has been identified ${ }^{9,10}$.

Neurodegenerative diseases, such as Alzheimer's disease $\mathrm{AD})$ and others dementias, increase the risk of unprovoked seizures by six to ten times compared with dementia-free patients $^{6,11}$. Patients with longer standing disease seems to be more at risk of developing seizures or epilepsy than those with a shorter duration of the disease ${ }^{11}$. Neoplasias may occur at any age and can lead to epilepsy, however are more common after 40 years old ${ }^{2}$. Seizures are frequently initial symptoms of metastatic disease.

Traumatic brain injury, most of them following falls, is a significant cause of seizures in the elderly, reaching up to $20 \%$ of epilepsies in this age group ${ }^{12}$. Seemingly mild traumatic brain injury may become potentially severe for elders, notably for those under anticoagulants or antiplatelet prescription because of the risk of subarachnoid hemorrhage ${ }^{6}$.

Acute symptomatic seizures (provoked seizures) often occur in the elderly in the onset of acute illnesses such as stroke, traumatic brain injury or in the course of toxic or metabolic disorders.

Hospitalized elderly are often under multiple drugs (polypharmacy) prescription, have multiple comorbidities, which therefore make them an especially vulnerable and susceptible population to injuries resulting from epileptic seizures.

\section{METHODS}

Retrospective, cross-sectional study was performed on patients 60 years aged and older consecutively admitted due several neurological disorders, in a tertiary center in Salvador (Bahia, Brazil) from January $1^{\text {st }}, 2009$ through December $31^{\text {nd }}, 2010$. We analyzed charts of 782 hospitalized patients and selected from those, 120 patients whose onset of epilepsy or epileptic seizure was at their sixties and above (late-onset epilepsy). The group was subdivided in two (median age 75 years), with the purpose to compare etiologies. All patients were under assistance of the neurology team. We excluded patients in whom it was not possible to set the time of the onset of epilepsy or epileptic seizure and those who had epileptic seizures previous at the cutting age (60 years old). We also conducted a phone interview with patient or caregiver for further information, when necessary.

The diagnosis of epilepsy and epileptic seizures was established according to the concepts of Glossary of Descriptive Terminology for Ictal Semiology: Report of the International League Against Epilepsy (ILAE) Task Force on Classification and Terminology ${ }^{1}$. We used the recommendation for a definition of acute symptomatic seizure (early seizures) endorsed by ILAE Executive Committee ${ }^{13}$.

We analyzed the etiologies of epilepsy and epileptic seizures, severity, comorbidities such as systemic arterial hypertension, diabetes mellitus, dyslipidemia, age and gender.

The study was approved by the Research Ethics Committee of the São Rafael Hospital, Salvador, Brazil.

The statistical analysis was performed with SPSS, version 14.0. The etiological prevalence was described as proportion. The analysis was performed dividing the sample in two age groups by the median of 75 years: younger subgroup, under 75 years old $(56 / 47 \%)$, and the older subgroup (64/54\%), at 75 years old and older. The age was compared among the etiologic groups by variance analysis. The categorical variables were compared by the Chi-square and quantitative variables by $t$-Student and the non parametric Mann-Whitney test.

\section{RESULTS}

One hundred and twenty patients were enrolled in the study, aged $75 \pm 9.1$ years (mean \pm SD), $55 \%$ (66) females. Systemic arterial hypertension was the most common cardiovascular risk factor and it was found in 88\% (106) patients. Diabetes mellitus occurred in $32 \%$ (38) and dyslipidemia in $26 \%$ (31) patients. Duration disease was $1.1 \pm 2.2$ years (Table 1).

Status epilepticus occurred in $7.5 \%$ (9) patients. Acute symptomatic seizures were found in $7.5 \%$ (9) patients and were associated with antibiotic use (5 patients), alcohol use in patient with CVD and concomitant renal failure (1 patient), metabolic disorder (2 patients) and in the set of acute ischemic stroke (1 patient).

The type of epileptic seizure was ascertained in $61.8 \%$ (75) of patients. Generalized seizures were described in $37.2 \%$ (45) of patients and focal seizures in $24.6 \%$ (30) of them (Table 1). In the remaining cases there was not enough information in the medical records to allow seizures were classified.

\section{Etiological prevalence}

Ischemic stroke was the most important etiology (37\%), followed by hemorrhagic stroke (12\%), intracranial neoplasias (13\%), Alzheimer's disease (6.7\%), others dementias (4.7\%), metabolic disturbance (5.5\%), and others etiologies (brain injury sequel, normal pressure hydrocephalus, meningitis, 
Table 1. Clinical characteristics of the sample.

\begin{tabular}{lc}
\hline Variables & \\
\hline Sample size & 120 \\
Demographic data & $75 \pm 9.1$ \\
Age (years) & $66(55 \%)$ \\
Gender (female) & $18(15 \%)$ \\
Marital status (unmaried) & $19(16 \%)$ \\
Assistance by SUS & \\
Cardiovascular risk factors & $38(32 \%)$ \\
Diabetes & $106(88 \%)$ \\
Systemic arterial hypertension & $31(26 \%)$ \\
Dyslipidemia & \\
Clínical data of epilepsy & $1.1 \pm 2.2$ \\
Disease duration (years) & $9(7.5 \%)$ \\
Status epilepticus & $9(7.5 \%)$ \\
Acute symptomatic seizure & \\
Epileptic seizure type & \\
$\quad$ Generalized & $40(33 \%)$ \\
Secondarily generalized & $7(5.8 \%)$ \\
Simple partial & $16(13 \%)$ \\
Complex partial & $7(5.8 \%)$ \\
Myoclonic & $5(4.2 \%)$ \\
Not classified & $45(38 \%)$ \\
\hline
\end{tabular}

SUS: Sistema Único de Saúde.

hemangioma, anoxic encephalopathy, alcoholism, antibiotics), and unknown (21\%) (Figure 1).

The analyze of the subgroup of patients aged at least 75 years old (Figure 2) suggests that ischemic stroke is the main cause of epilepsy and epileptic seizures, however, with the progression of age there is a tendency toward increasing in neurodegenerative causes, eg, dementias. In the subgroup under 75 years of age, ischemic stroke becomes even more prevalent (Figure 3 and 4).

\section{DISCUSSION}

In our study, we identified 120 (15\%) hospitalized elderly patients with new-onset epilepsy and epileptic seizures. These patients had multiple comorbidities, being systemic arterial hypertension (88\%) and ischemic stroke (37\%) the two most common. Seizures were the main reason for hospitalization of only $18(15 \%)$ patients. The remaining patients were hospitalized due several neurological disorders.

We found more generalized (33\%) than focal seizures, and an even higher frequency of not classified seizures (38\%) unlike to what has been demonstrated in most studies on epilepsy and epileptic seizures in aging people. It's important to highlight that many seizures classified as generalized type in studies that did not use the electroencephalogram (EEG) in all patients, as our study, were indeed focal seizures with secondary generalization. This unexpected high proportion of generalized type seizures may probable represent indeed focal seizures which the onset of the event was not witnessed or described in medical records. There are few studies addressed to elderly hospitalized population in which comorbidities such as metabolic disturbances, anoxic encephalopathy, and seizures induced by drugs contribute to the occurrence of generalized seizures.

In our sample, the most common etiology associated with epilepsy and epileptic seizures was stroke (49\%), similar to others published studies ${ }^{14,15}$. However the majority of published studies did not stratify the etiological prevalence by age group. Of 120 patients, $88 \%$ had systemic arterial hypertension, the most significant risk factor for stroke ${ }^{10}$. When analyzing systemic arterial hypertension, diabetes mellitus and dyslipidemia, we found that none of these comorbidities was an independent risk factor for seizures.

Ischemic stroke (37\%) was more common than hemorrhagic stroke (12\%). Seizures are one of the most common sequelae of stroke, especially in high-risk subgroups, such as patients with cardiac arrhythmia, subarachnoid hemorrhage (SAH), transient ischemic attack, hyperlipidemia and also smokers $^{10,16,17}$. Study conducted in a cohort of 593 patients consecutively admitted in a stroke unit, found a prevalence rate of epileptic seizures of $11.6 \%$ and identified that those occurred more frequently in patients with more severe stroke and in sinus thrombosis. The location of stroke, including cortical versus subcortical, did not influence the risk of seizures. The authors also concluded that conventional vascular risk factors were not associated with the occurrence of post-stroke seizures $^{18}$. In a prospective study, acute symptomatic seizures occurred within the first week of stroke and they were more common in cases of intracerebral hemorrhage $(14 \%)^{19}$. The incidence of late seizure ranges from 3 to $14 \%^{14,20}$. Although post stroke epilepsy occurs more often after 3 months to 1 year, unprovoked seizures have been reported up to 14 years of initial vascular event ${ }^{20,21}$.

In our study we identified only one patient who developed acute seizures in the course of acute stroke. Hemorrhagic stroke and cortical location were independent predictors of acute symptomatic seizures in the prospective, multicentric study of 714 patients from 26 to 97 years old ${ }^{10}$. Perhaps the relative scarcity of cases of hemorrhagic stroke in this sample is explained by the fact that most of these patients were attended by the neurosurgery department of the hospital. A retrospective, case-control study, to evaluate prevalence and radiological subtypes of CVD in epilepsy and epileptic seizures of late onset found that CVD is significantly more prevalent in patients with late onset seizures than in controls. Signs of large vessel disease (cortical and subcortical infarcts), were present in $21.9 \%$ of cases versus $1.9 \%$ of controls $(\mathrm{p}<0.001)$ and signs of small vessels diseases (periventricular white matter or subcortical lesions, including leukoaraiosis) were found in $49.5 \%$ of cases versus $32.3 \%$ of controls $(\mathrm{p}<0.05)$. The small vessel disease seemingly associated with higher severity ${ }^{22}$. 


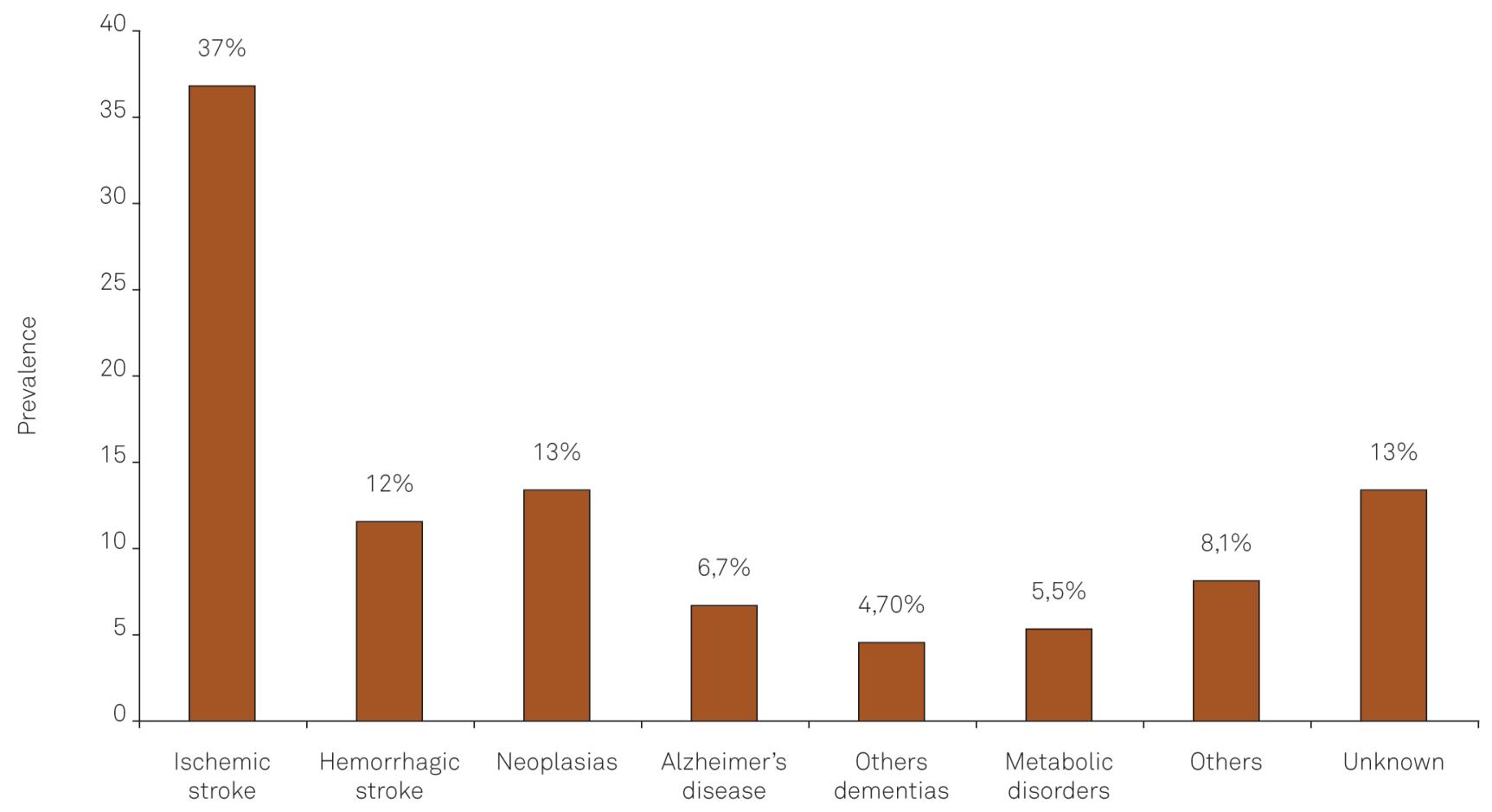

Figure 1. Etiological prevalence among the 120 patients.

In this sample $52 \%$ of patients had a diagnosis of epilepsy already done before admission, thus only $48 \%$ were submitted to neuroimaging exams during hospitalization, therefore we could not obtain enough data to correlate location and type of etiologic stroke with the epilepsy or epileptic seizure.

Dementias were the second most common etiology associated with epilepsy and epileptic seizures (18.9\%) in those older than age 75 years. In this subgroup, probable $A D$ was responsible for $10.9 \%$ of cases while for the remaining, the causes assigned of cognitive impairment were mixed dementia, vascular and Lewy Body. In $\mathrm{AD}$ patients, the frequency of epilepsy is $10 \%-22 \%$, which is in agreement with the results obtained in our study ${ }^{23}$. Epidemiological studies have shown that seizures or epilepsy are significantly more common in patients with dementia, about 6 to 10 times

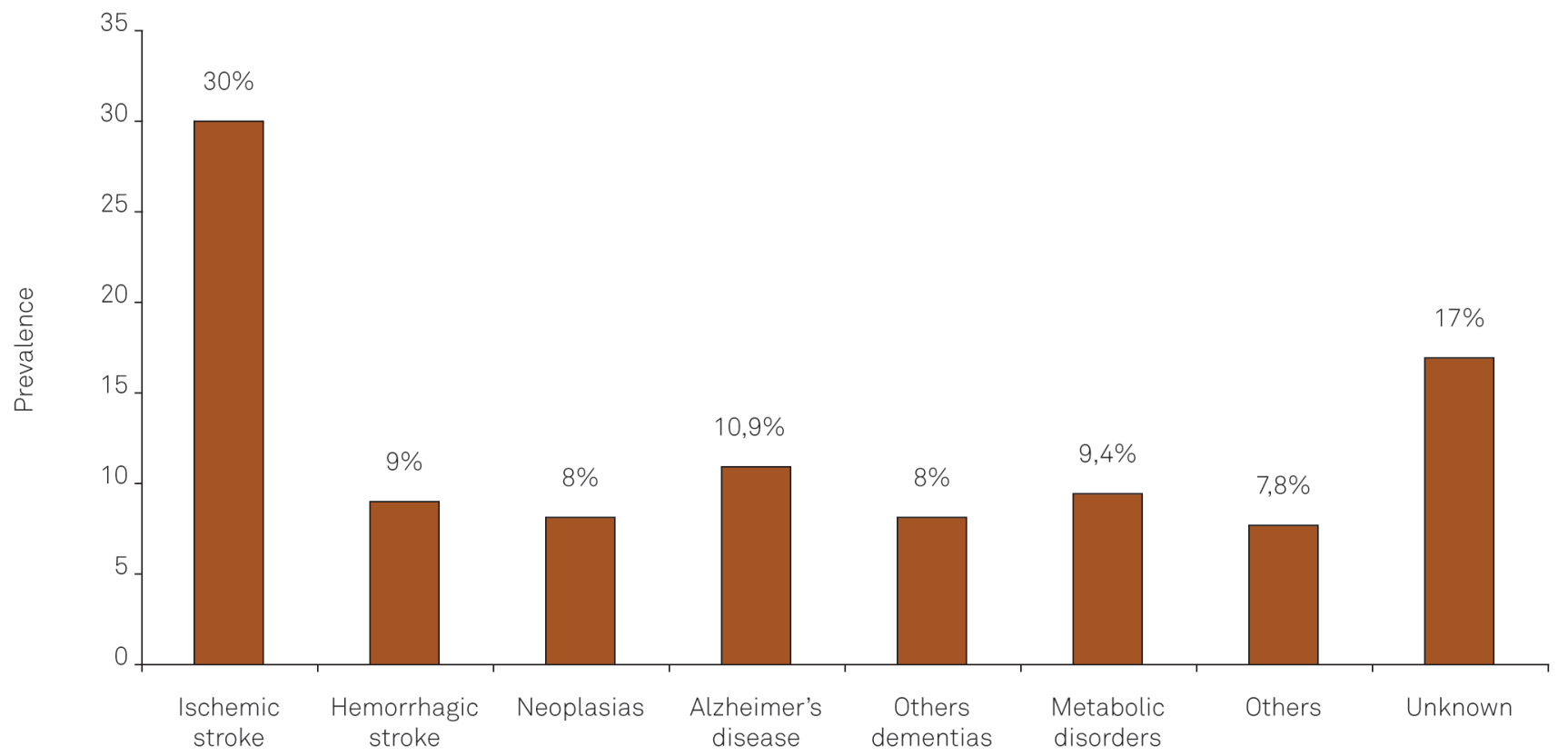

Figure 2. Etiological prevalence of epilepsy in the subgroup of patients aged at least 75 years old (median age). 


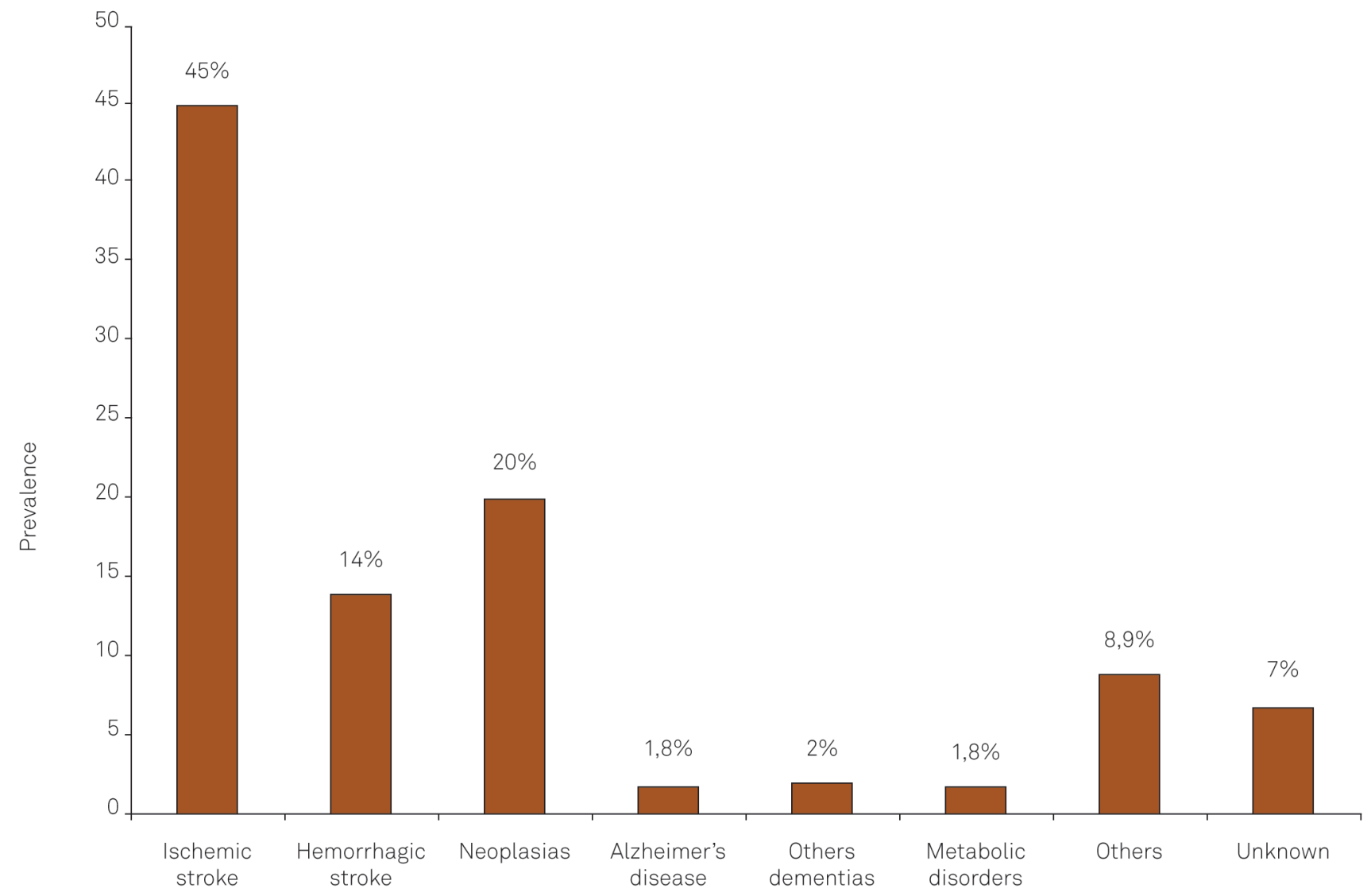

Figure 3. Etiological prevalence of epilepsy in the subgroup of patients younger than 75 years (median age).

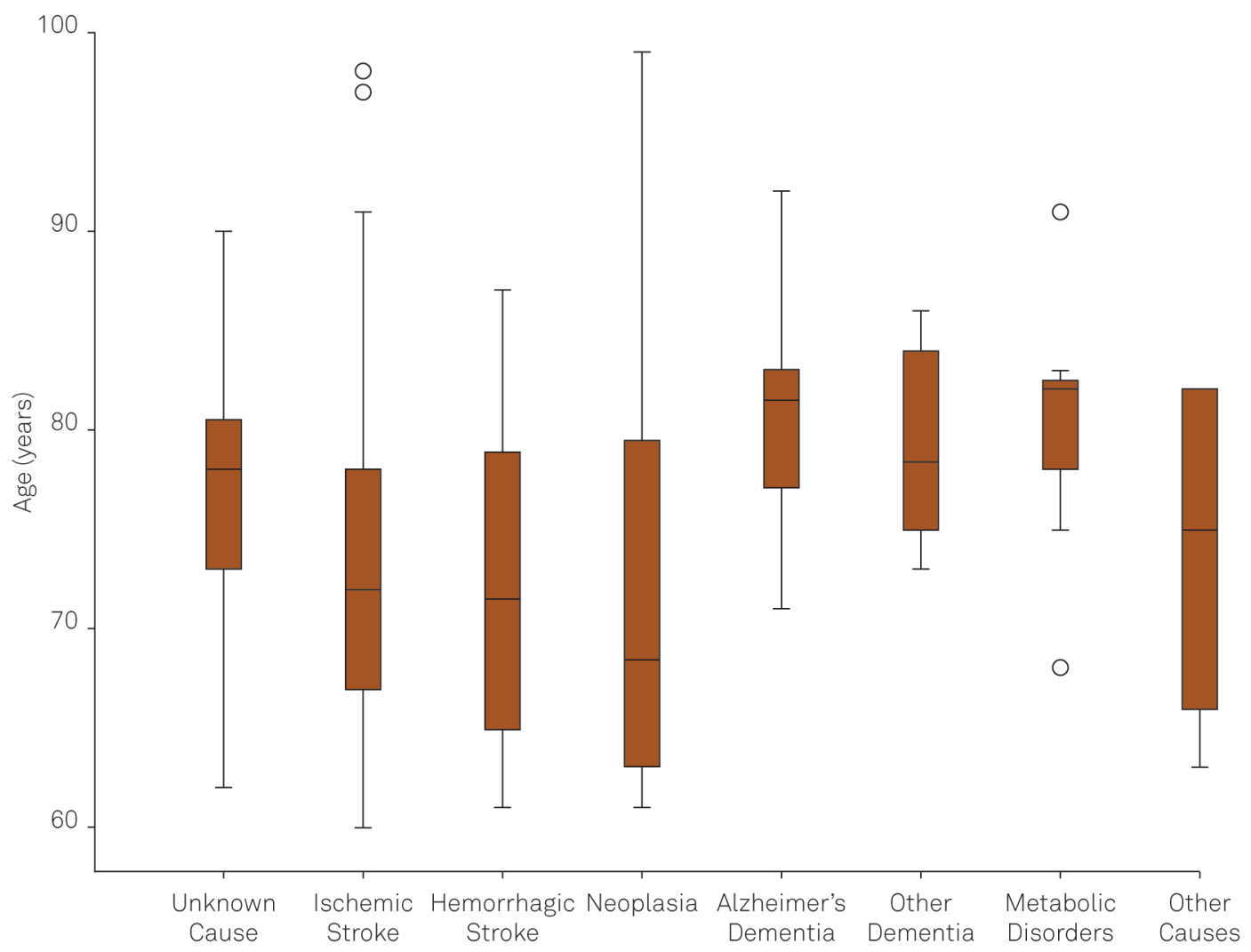

Figure 4. Comparison of age among subgroups defined by etiologies of epilepsy. $p$ value $=0.23$ for comparing between age groups. 
compared to the general population ${ }^{11,24}$. In some studies, as described in our sample, it was noted that $\mathrm{AD}$ patients with severe cognitive impairment and longer disease duration ( $\geq 3$ years), may be at greater risk of developing seizures than those with shorter duration of disease ${ }^{5,11}$.

Intracranial neoplasias were the second most frequent cause associated with epilepsy and epileptic seizures (20\%) in the subgroup aged below 75 years. Brain metastases (lung, bladder, pancreas, esophagus, liver, breast, uterus and colon), were the most prevalent malignancies, occurring in 11 patients. In the remaining cases, the primary tumors were: primary central nervous system (CNS) lymphoma, meningioma, anaplastic ependymoma and anaplastic astrocytoma. Elders with brain tumors are less likely to present seizures than younger patients, but age is a risk factor for increased mortality in those who develop seizures 5 .

Metabolic disorders occurred more frequently in the subgroup older than 75 years old (9.4\%), and the main causes were uremia, liver failure, hypoglycemia, hyponatremia and hypoxia. Metabolic disorders are responsible for 10 to $15 \%$ of seizures in the elderly ${ }^{25}$. Acute symptomatic seizures in the elderly, like occur in young individuals may be secondary to acute complications such as fever, liver or renal diseases and electrolyte disturbances.

In the group of other etiologies, five patients had seizures associated with the use of drugs with potential proconvulsant effects such as antibiotics like quinolones (3 patients used ciprofloxacin), and beta-lactams (2 patients used carbapenems). This group of patients had severe diseases associated with other several conditions known to be related with increased risk of seizures, such as meningitis, septicemia and metabolic encephalopathy. Elders, especially those hospitalized, are a vulnerable population and are exposed to high risk of experiencing seizures precipitated by drugs. A large study involving 1.754 patients treated with imipenem / cilastatin, to assess risk factors for seizures, concluded that patients with drug-related seizures had lower creatinine clearance, lower body weight, were older and more seriously illl ${ }^{26}$.

Nearly $10 \%$ of seizures in the elderly are associated with the use of alcohol and prescription drugs, and the most commonly known to lower the seizure threshold are the opioid analgesics (especially meperidine), the quinolones and beta-lactam antibiotics especially cephalosporin $3^{\text {rd }}$ and $4^{\text {th }}$, generation and carbapenems, tricyclic antidepressants and bupropion, theophylline, antipsychotic drugs (especially phenothiazines and clozapine) and isoniazid ${ }^{5,25,27,28}$. Study conducted in the UK, assessing data in the General Practice Research Database, concluded that 10\% of prescriptions of antiepileptic drugs (AEDs) in adults were associated with coprescription of at least one proconvulsant drug $^{27}$. Drug-induced seizures are potentially related to the use of more than one drug, high doses, parenteral administration and comorbidity. Convulsive and non-convulsive status epilepticus have been related to prescription drugs. It is estimated that $15 \%$ of patients with seizures secondary to drug use can develop status epilepticus ${ }^{28}$. The frequency and severity of adverse effects of drugs tend to be higher in the elderly, due to the progressive decline of the regulatory mechanisms of homeostasis. The elderly have an increased sensitivity to low seizure threshold, and therefore may be more susceptible to epileptiform activity ${ }^{29}$. Furthermore, elderly patients with epilepsy and under use of AED, are often in polypharmacy becoming then more prone to adverse effects of the pharmacokinetic and pharmacodynamics interactions between drugs ${ }^{27}$.

In our sample, one patient had seizures by AED withdrawal. We found no studies addressed to discontinuation of use of AEDs in this population, probably because most seizures have structural-metabolic cause and so these patients are at high risk for seizure recurrence after AED withdrawal. One chronic alcoholic patient had recurrent generalized seizures precipitated by alcohol. In this case, seizures were not caused by alcohol withdrawal, but occurred during the period of drug intake.

Despite the scarcity of complementary tests performed during hospitalization, only a small number of patients $(12.5 \%)$ had no etiological diagnosis elucidated. In a retrospective analysis of 130 patients older than age 50 years who were hospitalized with a diagnosis of epilepsy, $22.3 \%$ had not identified the possible causes of seizures ${ }^{30}$. The large number of symptomatic etiologies in hospitalized patients contrasts with the high frequency of unknown causes in population studies. The opportunity of readiness in investigation in hospitalized patients resulted in higher rate of etiological definition compared to previously reported data.

The most important limitation of our study is related to its retrospective design. We could not obtain all the information needed to answer important questions such as, seizures description, the time interval between the stroke diagnosis (in the case of stroke as etiology) and the onset of seizures. The attempts to get those answers, by contact with family, were not always succeeded, especially when the patient at issue had already died. On the other hand, diagnosis by ICD 10 (International Classification of Diseases) at discharge not always considered the diagnosis of seizures, convulsions or epilepsy, as many patients were discharged by another physician rather than the neurologist.

It is crucial to identify the risk factors and the many conditions associated with new-onset epilepsy in the elderly, especially those related to the hospital environment, considering that they may predispose the brain to seizures. Seizures of unknown etiology in the elderly require neurological and clinical investigation, and neuroimaging studies in the follow up, in order to diagnose neoplasias or cerebrovascular disease that has not been demonstrated in their initial approach.

Future clinical studies addressed to the elderly with epilepsy may contribute to providing better quality of care for this population. 
We conclude that, in this population of hospitalized elderly, epilepsy and epileptic seizures were mainly due to stroke, neoplasias and dementia. Ischemic stroke was the most important cause of late-onset seizures.

\section{REFERENCES}

1. Blume WT, Lüders HO, Mizrahi E, Tassinari C, Emde Boas W, Engel Jr J. Glossary of descriptive terminology for ictal semiology: report of the ILAE task force on classification and terminology. Epilepsia. 2001;42(9):1212-8. http://dx.doi.org/10.1046/j.1528-1157.2001.22001.x

2. Carpio A, Hauser WA. Epilepsy in the developing world. Curr Neurol Neurosci Rep. 2009;9(4):319-26. http://dx.doi.org/10.1007/s11910$009-0048-z$

3. Trinka E, Bauer G, Oberaigner W, Ndayisaba JP, Seppi K, Granbichler CA. Cause-specific mortality among patients with epilepsy: results from a 30-year cohort study. Epilepsia. 2013;54(3):495-501. http://dx. doi.org/10.1111/epi.12014

4. Huber DP, Griener R, Trinka E. Antiepileptic drug use in Austrian nursing home residents. Seizure.2013;22(1):24-7. http://dx.doi.org/ 10.1016/j.seizure.2012.09.012

5. Stephen LJ, Brodie MJ. Epilepsy in elderly people. Lancet. 2000;355 (9213):1441-6. http://dx.doi.org/10.1016/S0140-6736(00)02149-8

6. Johnston A, Smith PE. Epilepsy in the elderly. Expert Revf Neurother. 2010;10(12):1899-910. http://dx.doi.org/10.1586/ern.10.170

7. Berg AT. Epilepsy is common in the elderly, but where does it go? Neurology. 2012;78(7):444-5. http://dx.doi.org/10.1212/WNL.0b013e318246d70b

8. Cloyd J, Hauser W, Towne A, Ramsay R, Mattson R, Gilliam F et al. Epidemiological and medical aspects of epilepsy in the elderly. Epilepsy Res. 2006;68 Suppl 1:S39-48. http://dx.doi.org/10.1016/j. eplepsyres.2005.07.016

9. Brodie MJ, Elder AT, Kwan P. Epilepsy in later life. Lancet Neurol. 2009;8(11):1019-30. http://dx.doi.org/10.1016/S1474-4422(09)70240-6

10. Beghi E, D’Alessandro R, Beretta S, Consoli D, Crespi V, Delaj L et al. Incidence and predictors of acute symptomatic seizures after stroke. Neurology. 2011;77(20):1785-93. http://dx.doi.org/10.1212/ WNL.0b013e3182364878

11. Imfeld P, Bodmer M, Schuerch M, Jick SS, Meier CR. Seizures in patients with Alzheimer's disease or vascular dementia: a population-based nested case-control analysis. Epilepsia. 2013;54 (4):700-7. http://dx.doi.org/10.1111/epi.12045

12. Verellen RM, Cavazos JE. Pathophysiological considerations of seizures, epilepsy, and status epilepticus in the elderly. Aging Dis. 2011;2(4):278-85.

13. Beghi E, Carpio A, Forsgren L, Hesdorffer DC, Malmgren K, Sander JW et al. Recommendation for a definition of acute symptomatic seizure. Epilepsia. 2010;51(4):671-5. http://dx.doi.org/10.1111/j.1528-1167. $2009.02285 . x$

14. Silverman IE, Restrepo L, Mathews GC. Poststroke seizures. Arch Neurol. 2002;59(2):195-201. http://dx.doi.org/10.1001/archneur.59. 2.195

15. Kwan J, Wood E. Antiepileptic drugs for the primary and secondary prevention of seizures after stroke. Cochrane Database Syst Rev. 2010:CD005398. http://dx.doi.org/10.1002/14651858.CD005398.pub2.
16. Leppik IE, Birnbaum AK. Epilepsy in the elderly. Ann N Y Acad Sci 2010;1184(1):208-24. http://dx.doi.org/10.1111/j.1749-6632.2009. 05113.x

17. Herman ST. Early poststroke seizures: is it time for prospective treatment trials? Neurology. 2011;77(20):1776-8. http://dx.doi.org/ 10.1212/WNL.0b013e31823b4e73

18. Conrad J, Pawlowski M, Dogan M, Kovac S, Ritter MA, Evers S Seizures after cerebrovascular events: Risk factors and clinical features. Seizure. 2013;22(4):275-82. http://dx.doi.org/10.1016/j. seizure.2013.01.014

19. De Herdt V, Dumont F, Hénon H, Derambure P, Vonck K, Leys D et al. Early seizures in intracerebral hemorrhage: incidence, associated factors, and outcome. Neurology. 2011;77(20):1794-800. http://dx. doi.org/10.1212/WNL.0b013e31823648a6

20. Olsen TS. Post-stroke epilepsy. Curr Atheroscler Rep. 2001;3(4):340-4. http://dx.doi.org/10.1007/s11883-001-0029-4

21. Van Cott AC. Epilepsy and EEG in the elderly. Epilepsia. 2002;43 Suppl 3:94-102. http://dx.doi.org/10.1046/j.1528-1157.43.s.3.10.x

22. Maxwell H, Hanby M, Parkes LM, Gibson LM, Coutinho C, Emsley HC Prevalence and subtypes of radiological cerebrovascular disease in late-onset isolated seizures and epilepsy. Clin Neurol Neurosurg. 2013;115(5):591-6. http://dx.doi.org/10.1016/j.clineuro.2012.07.009

23. Mendez M, Lim G. Seizures in elderly patients with dementia epidemiology and management. Drugs Aging . 2003;20(11):791-803. http://dx.doi.org/10.2165/00002512-200320110-00001

24. Hesdorffer DC, Hauser WA, Annegers JF, Kokmen E, Rocca WA Dementia and adult-onset unprovoked seizures. Neurology. 1996;46(3):727-30. http://dx.doi.org/10.1212/WNL.46.3.727

25. Waterhouse E, Towne A. Seizures in the elderly: Nuances in presentation and treatment. Cleve Clin J Med.e 2005;72 Suppl 3: S26-37. http://dx.doi.org/10.3949/ccjm.72.Suppl_3.S26

26. Calandra G, Lydick E, Carrigan J, Weiss L, Guess H. Factors predisposing to seizures in seriously ill infected patients receiving antibiotics: experience with imipenem/cilastatin. Am J Med. 1988;84 (5):911-8. http://dx.doi.org/10.1016/0002-9343(88)90071-X

27. Shorvon SD, Tallis RC, Wallace HK. Antiepileptic drugs: coprescription of proconvulsant drugs and oral contraceptives: a national study of antiepileptic drug prescribing practice. J Neurol Neurosurg Psychiatry. 2002;72(1):114-5. http://dx.doi.org/10.1136/jnnp.72.1.114

28. Misra UK, Kalita J, Chandra S, Nair PP. Association of antibiotics with status epilepticus. Neurol Sci. 2013;34(3):327-31. http://dx.doi.org/ 10.1007/s10072-012-1001-5.

29. Messing RO, Closson RG, Simon RP. Drug-induced seizures: a 10-year experience. Neurology. 1984;34(12):1582-6. http://dx.doi.org/10.1212/ WNL.34.12.1582

30. Paradowski B, Zagrajek MM. Epilepsy in middle-aged and elderly people: a three-year observation. Epileptic Disord. 2005;7(2):91-5. 